small-field motion? It is generally agreed that these elements are inhibited, as the FD1-cell, in some way by cells with the same preferred direction but larger receptive fields $[1-4]$. To my knowledge, however, neither the elements responsible for this large-field inhibition nor the underlying synaptic mechanism could be characterized so far in any of these systems. The present findings on the mechanism of smallfield tuning of the FD1-cell, thus, demonstrates the significance of the fly for an understanding of fundamental principles of visual information processing in term of neuronal circuits.

I am grateful to A. Borst, T. Quenzer, W. Reichardt, and J. M. Zanker for critical discussions and for reading the manuscript. The figure is due to the skill of B. Pilz.
Received February 14, 1990

1. Collett, T. S.: Nature 232, 127 (1971)

2. Olberg, R. M.: J. Comp. Physiol. 141, 327 (1981)

3. Frost, B. J., Nakayama, K.: Science $220,744(1983)$

4. Allman, J., Miezin, F., McGuinness, E.: Perception 14, 105 (1985)

5. Egelhaaf, M.: Biol. Cybern. 52, 195 (1985)

6. Egelhaaf, M.: ibid. 52, 267 (1985)

7. Egelhaaf, M., Hausen, K., Reichhardt, W., Wehrhahn, C.: Trends Neurosci. 11, 351 (1988)

8. Reichardt, W., Egelhaaf, M., Guo, A.: Biol. Cybern. 61, 327 (1989)

9. Borst, A., Egelhaaf, M.: Trends Neurosci. 12, 297 (1989)

10. Egelhaaf, M.: Biol. Cybern. 52, 123 (1985)

11. Hausen, K.: Dissertation Univ. Tübingen 1976
12. Hausen, K.: Z. Naturforsch. 31 c, 629 (1976)

13. Hausen, K.: Verh. Dtsch. Zool. Ges. 74, $49(1981)$

14. Hausen, K., in: Photoreception and Vision in Invertebrates, p. 523 (ed. Ali, M A.). New York: Plenum 1984

15. Eckert, H., Dvorak, D. R.: J. Insect. Physiol. 29, 547 (1983)

16. Meyer, E. P., Matute, C., Streit, P., Nässel, D. R.: Histochemistry 84, 207 (1986)

17. Benson, J. A., in: Neurotox '88: Molecular basis of drug and pesticide action (ed. Lunt, G. G.). Amsterdam: Elsevier 1988

18. Schmid, A., Bülthoff, H.: Biol. Cybern 59, 71 (1988)

19. Egelhaaf, M., Borst, A., Pilz, B.: Brain Res. 509, 156 (1990)

20. Hausen, K., Egelhaaf, M., in: Facets of Vision (eds. Stavenga, D., Hardie, R.). Berlin-Heidelberg-New York: Springer 1989
Naturwissenschaften 77, $185-186(1990)$ (C) Springer-Verlag 1990

\section{The Seasonal Variation of the Angular Momentum of the Oceans}

\author{
P. Brosche and J. Wünsch \\ Sternwarte der Universität, D-5300 Bonn
}

\author{
A. Frische and J. Sündermann \\ Institut für Meereskunde der Universität, D-2000 Hamburg \\ E. Maier-Reimer and U. Mikolajewicz \\ Max-Planck-Institut für Meteorologie, D-2000 Hamburg
}

The main part of the seasonal variation of the (solid) Earth's angular velocity $\omega$ is caused by an exchange of angular momentum between the atmosphere and the solid Earth [1]. Observationally, the balance can be confirmed with an accuracy of about $10 \%$ of the variation [2]. The interchange with the oceans usually has been assumed to be small. In this article we present computations of its amount and phase.

Preliminary attempts to estimate the oceanic contribution from geostrophic currents based on insufficient data sets failed by one order of magnitude [3].
Here, we present results of a more advanced large-scale circulation model for the world ocean [4]. Laterally, this model resolves the circulation in grid steps of $3^{\circ} .5$. The vertical resolution involves 11 levels with 7 of them placed in the uppermost kilometer where the seasonal signal prevails. The model circulation was induced by seasonally varying boundary conditions at the sea surface. After 5000 years of model time the circulation had sufficiently adjusted to the forcing and reached a stationary state. We analyzed the model results for the final year of integration.
In this way, we obtained the angular momentum content $J_{\text {rel }}$ of the oceanic motions and the variations in the moment of inertia $\theta$ due to variations in sea level and density (strictly speaking, of their components around the Earth's axis of rotation). As expected, contributions of changes in the density stratification and changes in surface elevation almost compensate each other. The resulting net effect on seasonal variations in the moment of inertia amounts to about $10 \%$ of the density contribution. Each change $J_{\text {rel }}$ or $\Delta \theta \cdot \omega$ of the angular momentum of the oceans must be accompanied by a counteracting change of that of the solid Earth in order to retain the total. The two quantities and their effect $\Delta \omega$ on the angular velocity of the solid Earth are shown in Fig. 1a and b, together with an analytical approximation (Fourier series of up to the 2 nd degree). While the variation of $\theta$ requires at least a 2 nd degree representation, the currents reveal a simple sine wave. This difference probably results from a serious limitation in our applied forcing functions: for the Southern Ocean, in particular, there is a general lack of adequate data for wind stress and for seasurface values of temperature and 
salinity. Available data sets for the climatological wind forcing do not reveal the typical semiannual oscillation known from fluctuations of the Antarctic Circumpolar Current [5] and [6].

When we add the two effects of $J_{\text {rel }}$ and $\theta$ we arrive at total oceanic changes of the Earth's angular velocity or length from fluctuations in sea-level pressure

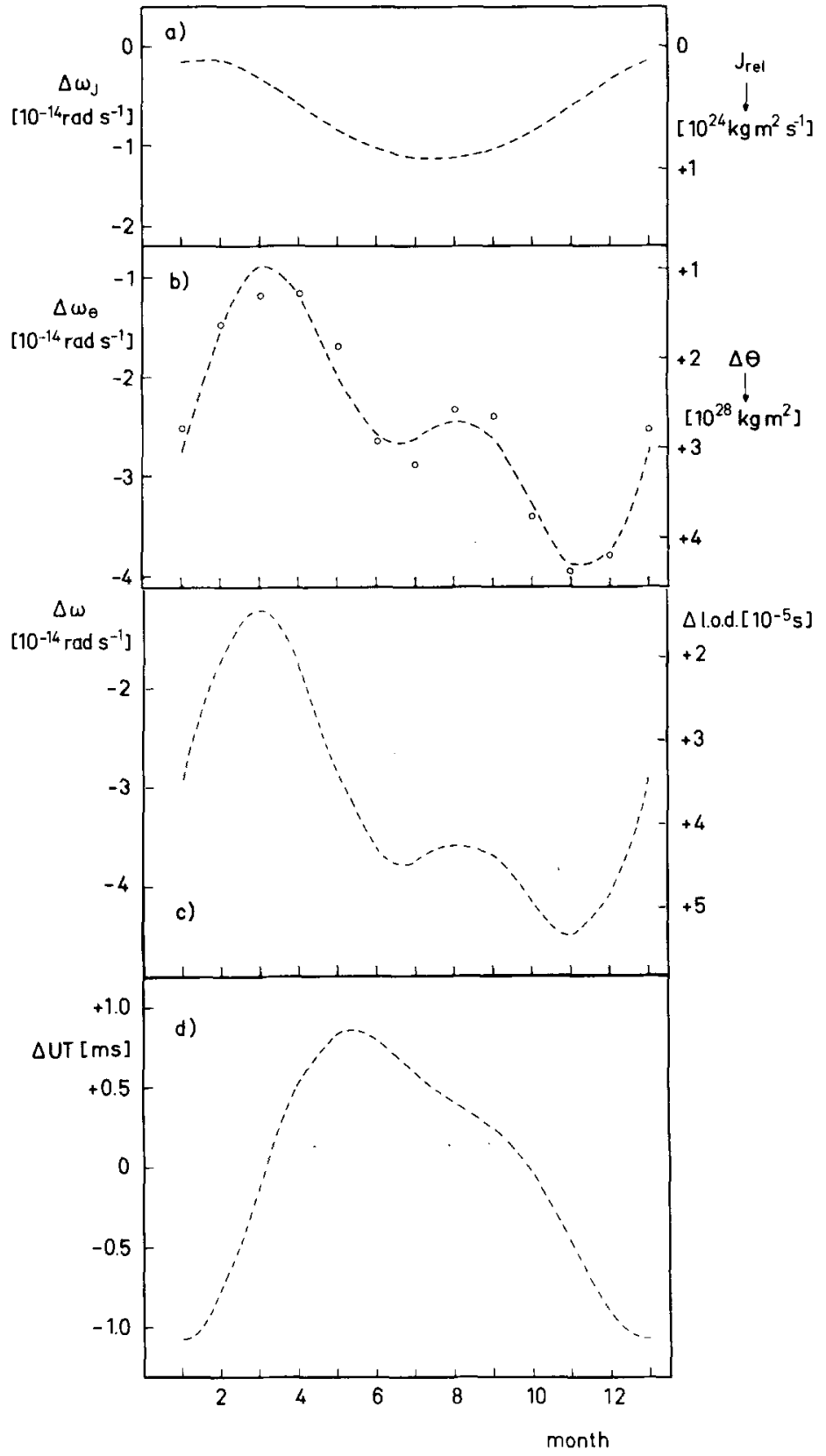

Fig. 1. The smooth curves are Fourier approximations of the 2 nd degree; individual monthly values are shown if it is possible to recognize the deviation from the curve. The zero points are arbitrary. a) Average annual variation of the axial oceanic angular momentum $J_{\text {rel }}$ due to motions of the water relative to the solid Earth and the corresponding change $\Delta \omega_{\mathrm{f}}$ in the angular velocity of the solid Earth. b) Average annual variation of the oceanic moment of inertia $\theta$ around the rotation axis of the Earth and the corresponding change $\Delta \omega_{\theta}$. c) Total change in angular velocity $\Delta \omega$ and length of day of the solid Earth from the combination of (a) and (b). d) Change in Universal Time (rotation angle) from integration of (c) of day (Fig. 1c) and by integration at changes in Universal Time (Fig. 1d). An amplitude of about $1 \mathrm{~ms}$ in UT is not negligible as compared with accuracies in Very Long Baseline Interferometry of typically $0.1 \mathrm{~ms}$ at these time scales [7]. It should be noted that our interpretation does not touch the question of the interaction between the three components of the Earth. Both the angular momenta of the atmosphere and the solid Earth are $o b$ served quantities. It is a problem of the observational precision whether one can already recognize a significant imbalance between these two constituents [8]; if this is the case one could try to explain it by the oceanic contribution. We are quite confident in the existence of the latter in the order of magnitude given in this report.

Received August 21, 1989 and January 26, 1990

1. Barnes, R. T. H., Hide, R., White, A. A., Wilson, C. A.: Proc. Roy. Soc. A 387, 31 (1983)

2. Dickey, J. O., Eubanks, T. M., Steppe, J. A., in: Earth Rotation: Solved and unsolved problems, p. 137 (ed. A. Cazenave). Dordrecht: Reidel 1986

3. Frische, A., Sündermann, J., in: Earth Rotation from Eons to Days (eds. P. Brosche, J. Sündermann). Berlin: Springer (in press)

4. Maier-Reimer, E., Mikolajewicz, U., Hasselmann, K.: J. Phys. Ocean (submitted)

5. Brosche, P., Sündermann, J.: Dtsch. hydrogr. Z. 38, 1 (1985)

6. Van Loon, H.: J. Atmos. Sci. 24, 472 (1967)

7. Schuh, H., in: The earth's rotation and reference frames for geodesy and geodynamics, p. 171 (eds. A. K. Babcock, G. A. Wilkins). Dordrecht: Kluwer 1988

8. NASA Geodynamics Programme, Summary Report 1979-1987. NASA Techn. Memorandum 4065, p. 37. NASA 1988 